CLINICAL STUDY

\title{
Beyond the morphology of the glucose curve following an oral glucose tolerance test in obese youth
}

\author{
Giuseppe Nolfe, Maria Rita Spreghini ${ }^{1}$, Rita Wietrzycowska Sforza ${ }^{1}$, Giuseppe Morino ${ }^{1}$ and Melania Manco ${ }^{2}$ \\ Institute of Cybernetics 'E. Caianiello', National Research Council of Italy-CNR, Pozzuoli, Italy, ${ }^{1}$ Unit of Clinical Nutrition and ${ }^{2}$ Scientific Directorate, \\ Bambino Gesù Hospital, IRCCS, Piazza SanOnofrio 4, I-O0165 Rome, Italy
}

(Correspondence should be addressed to M Manco; Email: melania.manco@opbg.net)

\begin{abstract}
Background: To describe the morphology of glucose curve during the oral glucose tolerance test (OGTT) and any association with glucose tolerance, insulin action and secretion in obese youth. Study design: Cross-sectional.

Methods: OGTT data of 553 patients were analysed. Subjects were divided in groups based on the morphology (i.e. monophasic, biphasic, triphasic and upward monotonous) of glucose curve. Insulin action was estimated by the homeostasis model assessment of insulin resistance, the insulin sensitivity, the muscle insulin sensitivity and the hepatic insulin resistance indexes (HIRI), and the oral glucose insulin sensitivity (OGIS). Insulin secretion was estimated by the insulinogenic index (IGI). Disposition index, including the insulin secretion-sensitivity index-2, and areas under glucose $\left(\mathrm{AUC}_{\mathrm{G}}\right)$ and insulin $\left(\mathrm{AUC}_{\mathrm{I}}\right)$ curves were computed.

Results: In patients with normal glucose tolerance $(n=522)$, prevalent morphology of the glucose curve was monophasic $(n=285,54 \%)$. Monophasic morphology was associated with the highest concentration of $1 \mathrm{~h}$ plasma glucose $(P<0.0001)$ and $\mathrm{AUC}_{\mathrm{G}}(P<0.0001)$; biphasic morphology with better insulin sensitivity as estimated by OGIS $(P<0.03)$ and lower $\mathrm{AUC}_{\mathrm{I}}(P<0.0001)$; triphasic morphology with the highest values of HIRI $(P<0.02)$ and IGI $(P<0.007)$.By combining morphologies of glucose and insulin curves or time of the glucose peak, a deeper characterisation of different phenotypes of glucose metabolism emerged.

Conclusions: Morphologies of the glucose curve seem reflecting different metabolic phenotypes of insulin action and secretion, particularly when combined with morphologies of insulin curve or time of glucose peak. Such findings may deserve validation in cohort study, in which glucose metabolism would be estimated by using gold standard techniques.
\end{abstract}

European Journal of Endocrinology 166 107-114

\section{Introduction}

Altered glucose metabolism and type 2 diabetes mellitus enclose a group of metabolic diseases characterised by altered glycaemia resulting from defects in insulin secretion, action (insulin resistance increased in the skeletal muscle and/or liver) or both (1).

Surrogate measures of insulin action and secretion can be obtained from plasma glucose and insulin during the oral glucose tolerance test (OGTT) (1). Such indexes can be helpful for deeper phenotyping of individuals with altered glucose metabolism and tracking the natural history of the disease.

During the OGTT, insulin action and secretion would modulate the rate of increase and decrease in plasma glucose, and time required for plasma glucose to peak and to return to the fasting levels (2). First-phase insulin secretion and hepatic insulin resistance index (HIRI) are important determinants of the initial rise of plasma glucose following glucose ingestion. The rate of decline in plasma glucose concentration back towards the fasting levels seems to depend prevalently on late-phase insulin secretion and muscle insulin sensitivity (3). In that, the shape that the glucose curve assumes during the OGTT results from the net and dynamic balance between insulin action and secretion.

Few studies have attempted to answer the question of whether the shape of the glucose curve over the time following the OGTT predicts the risk of altered glucose metabolism and harbours metabolic information not captured by the level of glycaemia alone (4-7). Findings of such studies appear to be still inconsistent.

In this study, we aim to describe the morphology of the glucose curve following the glucose load in a sample of Caucasian obese children and adolescents, together with morphologies of the insulin curve and time of glucose peaking. As researchers did in the past (4-7), we speculate that different morphologies of the glucose and insulin curves may resemble differences in insulin action and secretion. 


\section{Materials and methods}

Data from 553 Caucasian youngsters were retrospectively analysed. Patients were consecutively referred for overweight by general paediatricians to the Unit of Clinical Nutrition at the 'Bambino Gesù' Hospital from January 2008 to December 2010. Inclusion criteria were age ranging from 4 to 18 years; obesity (body mass index (BMI) $\geq 95$ th percentile for age and sex) (8) with no previous treatment for obesity, no systemic and endocrine disease, no previous diagnosis of impaired fasting glucose, impaired glucose tolerance (IGT) or diabetes (9), and no use of medication, alcohol or recreational drugs. Weight and height were measured following standard procedures. The BMI $z$-score was calculated using US reference values (8).

The study protocol conformed to the guidelines of the European Convention of Human Rights and Biomedicine for Research in Children and to those of the Ethics Committee of the 'Bambino Gesù' Hospital.

\section{Oral glucose tolerance testing}

Glucose tolerance was classified according to the criteria of the American Diabetes Association classification (9). A standard OGTT $(1.75 \mathrm{~g} / \mathrm{kg}$ body weight up to $75 \mathrm{~g})$ was performed with flavoured glucose (Glucosio Sclavo Diagnostics, Sovicille, SI, Italy $75 \mathrm{~g} / 150 \mathrm{ml}$ ) after 8$10 \mathrm{~h}$ overnight fast. After local application of an aesthetic cream (EMLA Cream), one ante-cubital i.v. catheter was inserted for blood sampling and was maintained patent by a normal saline drip during the test. Two baseline samples were obtained at $-15^{\prime}$ and $0^{\prime}$ followed by sampling at $30^{\prime}, 60^{\prime}, 90^{\prime}$ and $120^{\prime}$ for measurements of plasma glucose and insulin.

A parameter of glucose tolerance (10) was calculated taking into account the glucose peak $G_{p}(\mathrm{mg} / \mathrm{dl})$ irrespective of the time when the peak is reached:

$\mathrm{GT}_{\mathrm{p}}=\frac{10^{6}}{\mathrm{G}_{p}^{2}\left(G_{p}-70\right)}$.

This parameter may have a more significant meaning than the glucose levels at arbitrarily chosen intervals of $60^{\prime}, 90^{\prime}$ or $120^{\prime}$, as the glucose peak may occur at different times in each individual and combines peripheral insulin activity and $\beta$-cell secretory function (10).

The homeostasis model assessments of fasting insulin resistance (HOMA-IR) was computed according to Matthews et al. (11): HOMA - IR $=\left(I_{0}-G_{0}\right) / 22.5$, with glucose and insulin expressed as mmol/l and $\mu \mathrm{UI} / \mathrm{ml}$ respectively. The insulin sensitivity index (ISI) (12),

$\mathrm{ISI}=\frac{10^{4}}{\left(G_{0} \times I_{0} \times m_{G} \times m_{I}\right)^{1 / 2}}$ where $m_{G}$ and $m_{I}$ are the averaged glucose insulin concentration, and the oral glucose insulin sensitivity (OGIS) (13), were both computed with glucose expressed as $\mathrm{mg} / \mathrm{dl}$ and insulin measured in $\mu \mathrm{UI} / \mathrm{ml}$ respectively. We also estimated the HIRI by $\mathrm{AUC}_{G 0-30} \times$ $\mathrm{AUC}_{I 0-30}$, where $A U C$ is the area under the curve of glucose and insulin, respectively, in the interval between $0^{\prime}$ and $30^{\prime}$. AUCs were estimated using the trapezoidal integration rule and with glucose, insulin and time expressed as $\mathrm{mg} / \mathrm{dl}, \mu \mathrm{UI} / \mathrm{ml}$ and minutes respectively. The skeletal muscle insulin sensitivity (MISI) was evaluated with the aforementioned units of measurements using the formula

$\frac{1}{m_{I}} \times \frac{\Delta G}{\Delta t}$

where $\Delta G$ is the plasma glucose decay from its peak to its nadir during the OGTT (3).

The insulin secretion was estimated by means of the following parameters: the insulinogenic index (IGI) (14) defined as

$$
\begin{gathered}
\mathrm{IGI}=\frac{I_{30}-I_{0}}{G_{30}-G_{0}}\left[\frac{\mu \mathrm{UI} / \mathrm{ml}}{\mathrm{mmol} / \mathrm{l}}\right], \\
\text { and the ratio } \frac{A U C_{I}}{A U C_{G}} .
\end{gathered}
$$

The disposition index (DI) was calculated as the product of IGI and ISI (DI ISI), OGIS ( $\left.\mathrm{DI}_{\mathrm{OGIS}}\right)$ or $A U C_{I} /$ $A U C_{G}$ (termed as insulin secretion-sensitivity index-2 (ISSI-2)) (15).

\section{Morphologies of the curves}

Subjects were divided in groups based on morphologies of glucose and insulin curves and peak time of glucose and insulin during the OGTT.

Briefly, the glucose or insulin concentration increases gradually and reaches its maximum after $2 \mathrm{~h}$ in those subjects classified as having a 'monotonous' curve.

Plasma glucose reaches its maximum value between $30^{\prime}$ and $90^{\prime}$ and then decreases in subjects with 'monophasic' curve. The levels of glucose at $90^{\prime}$ must not be less than that at $120^{\prime}$ and, in detail, $G_{120}-G_{90}<+4.5 \mathrm{mg} / \mathrm{dl}$, where $4.5 \mathrm{mg} / \mathrm{dl}$ is the measurement error for plasma glucose.

In the biphasic curve, the peak of the curve may occur at $30^{\prime}$ or $60^{\prime}$, but between $90^{\prime}$ and $120^{\prime}$, it still goes significantly up: $G_{120}-G_{90}>+4.5 \mathrm{mg} / \mathrm{dl}$. If the maximum is reached at $30^{\prime}$, we can also observe a slope between $60^{\prime}$ and $120^{\prime}: G_{120}-G_{60}>+4.5 \mathrm{mg} / \mathrm{dl}$ in some rare cases, a biphasic curve may present with the glucose peak at $120^{\prime}$.

The triphasic curve is characterised by double positive peaks at $30^{\prime}$ and $90^{\prime}$ and negative peak at $60^{\prime}$. For glucose, the following condition must be satisfied: $G_{120}-G_{90}<-4.5 \mathrm{mg} / \mathrm{dl}$. 
The same has been done in order to classify insulin curves.

Different morphologies of the glucose or insulin curves are reported in Fig. 1.

\section{Analytical methods}

Plasma glucose was immediately measured by the glucose oxidase technique (Cobas Integra; Roche). Insulin was measured by RIA (MYRIA Technogenetics, Milan, Italy).

\section{Statistical analysis}

Continuous data are reported as mean and S.E.M., with categorical data as counts and percentages. Skewed data were logarithmically transformed before comparisons.

$\chi^{2}$-test was used for categorical variables, and ANOVA followed by the post-hoc Bonferroni test for comparison among groups with different time peaks and morphologies. The Spearman rank correlations were investigated. The level of significance was set at $\alpha<0.05$. Data analysis was performed by using SPSS Statistical Software (SPSS V12.0, Inc., Chicago, IL, USA) and MatLab (Mathworks, Natick, MA, USA) for categorisation of curve morphologies and peak times.

\section{Results}

Data of 553 patients (Supplementary Table 1, see section on supplementary data given at the end of this article) were included in the analysis. Of the studied subjects, 522 had normal glucose tolerance (NGT), whilst $31(5.6 \%)$ met criteria for IGT. Statistically significant differences were observed between males
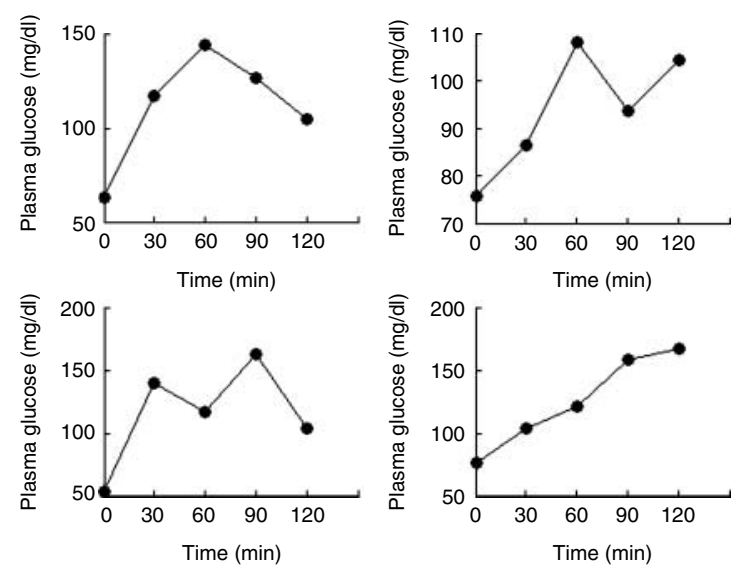

Figure 1 Monophasic (right hand) and biphasic (left hand) morphologies of the glucose curve are depicted in the upper panels, whilst triphasic and upward monotonous are in the lower panels. and females and groups with different glucose tolerance (Supplementary Table 2, see section on supplementary data given at the end of this article). NGT patients served for the analyses of morphology and peak time.

\section{Glucose and insulin peaks and curve morphologies during the OGTT in NGT individuals}

Tables 1 and 2 shows distributions of glucose and insulin peaks and curve morphologies following the oral test.

The glucose peak occurred most frequently at $30^{\prime}$ and was accompanied by the synchronous peak of insulin. No difference was observed among subjects with the glucose peak at different time points of the OGTT (data not shown).

Prevalent morphologies of the glucose curve were monophasic $(54.5 \%)$ or biphasic (33\%; Table 2). Different morphologies of the glucose curve were associated with significant differences in BMI $(P<0.001)$, FPG $(P<0.007), \mathrm{I}_{30} \quad(P<0.02), \mathrm{I}_{120}$ $(P<0.002)$, IGI $(P<0.007)$, HIRI $(P<0.02)$, $\mathrm{AUC}_{\mathrm{I}}$ $(P<0.04)$, OGIS $(P<0.01), 1 \mathrm{~h}$ plasma glucose (1HPG), 2HPG, glucose tolerance at the peak $\left(\mathrm{GT}_{\mathrm{p}}\right)$, MISI, $\mathrm{AUC}_{\mathrm{G}}$ and DI $(P<0.0001$ for all the latter comparisons; Table 3).

\section{Characterisation of NGT subjects with monophasic and/or biphasic shapes of the glucose and insulin curves}

As most of the NGT subjects had monophasic or biphasic shapes of glucose and insulin curves, we divided subjects belonging these groups $(n=387)$ in four subgroups: those having monophasic (MM group, $n=220$ ), biphasic (BB group, $n=19$ ) morphologies of both glucose and insulin curves, monophasic glucose and biphasic insulin curves (MB group, $n=110$ ) or vice versa (BM group, $n=38$; Fig. 2). The four groups differed significantly in BMI $z$-score $(P<0.01)$; waist circumference $(P<0.01)$; FPG $(P<0.04)$, FPI $(P<0.001)$, HIRI $(P<0.04)$, HOMA-IR $(P<0.003)$, ISI $(P<0.001)$, OGIS $(P<0.04)$, GT $_{\mathrm{p}}(P<0.01), \mathrm{AUC}_{\mathrm{I}}(P<0.02)$, ISSI-2 $(P=0.004)$ and 1HPG; 2HPG; and $\mathrm{I}_{120}$, MISI and $\mathrm{AUC}_{\mathrm{G}}(P<0000.1$ for all the latter comparisons $)$.

\section{Characterisation of NGT subjects with monophasic and/or biphasic shapes of the glucose and glucose peaking at $30^{\prime}$ or $60^{\prime}$}

We also investigated the differences between individuals $(n=454)$ with monophasic glucose curve and glucose peaks at $30^{\prime}\left(\mathrm{M}_{\mathrm{G} 30}, n=278\right)$ or $60^{\prime}\left(\mathrm{M}_{\mathrm{G} 60}, n=117\right)$, or biphasic peaking at $30^{\prime}\left(\mathrm{B}_{\mathrm{G} 30}, n=38\right)$ or $60^{\prime}\left(\mathrm{B}_{\mathrm{G} 60}\right.$, $n=19$; Fig. 3). Differences were observed in $1 \mathrm{HPG}$, HIRI, $\mathrm{I}_{30}, \mathrm{I}_{120}(P<0.0001$ for all the comparisons $)$, 
Table 1 Distribution of the glucose and insulin peaks following the glucose load in normal glucose tolerance obese patients.

\begin{tabular}{lccccc}
\hline & \multicolumn{5}{c}{ Time of the glucose peak (minutes) } \\
\cline { 2 - 5 } & 30 & 60 & 90 & 120 & $n$ \\
\hline Time of insulin peak (minutes) & & & & \\
30 & $238(45.6 \%)$ & $19(3.6 \%)$ & $13(2.5 \%)$ & $7(1.3 \%)$ & $277(53 \%)$ \\
60 & $48(9.2 \%)$ & $78(14.9 \%)$ & $4(0.8 \%)$ & $6(1.1 \%)$ & $136(26 \%)$ \\
90 & $17(3.2 \%)$ & $27(5.2 \%)$ & $13(2.5 \%)$ & $3(0.6 \%)$ & $60(11.5 \%)$ \\
120 & $14(2.9 \%)$ & $13(2.5 \%)$ & $7(1.3 \%)$ & $15(2.9 \%)$ & $49(9.2 \%)$ \\
$n$ & $317(60.5 \%)$ & $137(26.2 \%)$ & $37(7 \%)$ & $31(5.9 \%)$ & $522(100 \%)$ \\
\hline
\end{tabular}

2HPG $(P<0.05), \mathrm{AUC}_{\mathrm{G}}(P<0.003), \mathrm{AUC}_{\mathrm{I}}(P<0.009)$, OGIS $(P<0.04)$, ISI $(P<0.014)$, MISI $(P<0.006)$, IGI $(P<0.003)$, ISSI-2 $(P=0.005)$ and DI ISI $_{1}(P<0.002)$.

\section{Correlation analyses in NGT subjects}

The Spearman's $r_{o}$ was used to evaluate the association between 1HPG, 2HPG, $\mathrm{AUC}_{\mathrm{G}}$ and indexes of insulin sensitivity (ISI and OGIS) in the whole sample of NGT individuals and in subgroups identified by the different morphologies of the glucose curve.

In the whole sample of NGT subjects, $1 \mathrm{HPG}$ $\left(r_{o}=0.822\right)$ correlated better than 2HPG $\left(r_{o}=0.563\right)$ with $\mathrm{AUC}_{\mathrm{G}}$. In individuals with upward monotonous morphology, $r_{o}$ were 0.805 and 0.682 ; in those with monophasic shape 0.865 and 0.657 ; biphasic 0.722 and 0.522 , and triphasic 0.719 and 0.780 respectively $(P<0.0001$ in all the cases $)$.

The best correlations between ISI and OGIS $(P<0.0001$ in all the cases $)$ were observed in subjects with triphasic $\left(r_{o}=0.745\right)$ or monophasic morphologies $\left(r_{o}=0.688\right)$. The correlation was modest in subjects with biphasic curve $\left(r_{o}=0.591\right)$.

\section{Distribution of peaks and morphologies in IGT patients}

Morphology of the glucose curve was upward monotonous in five patients $(16 \%)$, monophasic in $16(52 \%)$ and biphasic in ten $(32 \%)$. The shape of the insulin curve was monotonous in ten patients $(32 \%)$, monophasic in eight (26\%), biphasic in 11 (35.5\%) and triphasic in two $(6 \%)$ patients. The glucose peak occurred more frequently at $60^{\prime}(n=14,45 \%)$. Three patients $(\sim 10 \%)$ had the glucose peak at $30^{\prime}$, eight $(26 \%)$ at $90^{\prime}$ and six of them at $120^{\prime}(19.4 \%)$.

\section{Discussion}

Differences in the morphology of the glucose curve following the OGTT, named as monophasic, biphasic, triphasic and upward monotonous, were associated with significant variation of parameters related to insulin action, sensitivity and glucose tolerance.

Prevalent morphologies of the glucose curve were monophasic in obese normo-tolerant young obese individuals, with glucose peaking more frequently at $30^{\prime}$ and $60^{\prime}$.

Monophasic morphology was associated with the highest values of $1 \mathrm{HPG}$ and the greatest $\mathrm{AUC}_{\mathrm{G}}$, which would represent a risk factor for altered glucose metabolism (5, 16, 17, 18). Indeed, Kanauchi et al. (4) observed that monophasic morphology occurs more frequently in IGT than in NGT adult individuals. When patients with monophasic morphology of the glucose curve were deeper characterised by describing the morphology of the insulin curve (Fig. 2), subjects with monophasic morphologies of both curves or biphasic insulin were those who exhibited greater excursion of $1 \mathrm{HPG}$ and $\mathrm{AUC}_{\mathrm{G}}$. Subjects with monophasic glucose and biphasic insulin had also the greatest HOMA-IR and HIRI, which both suggest an increased basal and not adequately suppressed endogenous glucose production (EGP), respectively, following the glucose load. EGP, together with reduced muscle insulin sensitivity, may contribute toward altered glucose tolerance in these

Table 2 Morphology of the glucose and insulin curves following glucose load in normal glucose tolerance obese patients.

\begin{tabular}{|c|c|c|c|c|c|}
\hline & \multicolumn{5}{|c|}{ Morphology of the glucose curve } \\
\hline & Monotonous & Monophasic & Biphasic & Triphasic & $n$ \\
\hline \multicolumn{6}{|c|}{ Morphology of the insulin curve } \\
\hline Monotonous & $9(1.72 \%)$ & $11(2.1 \%)$ & $1(0.2 \%)$ & - & $21(4 \%)$ \\
\hline Monophasic & $7(1.3 \%)$ & $192(36.8 \%)$ & $32(6.1 \%)$ & $7(1.3 \%)$ & $238(45.6 \%)$ \\
\hline Biphasic & $5(0.95 \%)$ & $58(11.1 \%)$ & $133(25.4 \%)$ & $8(1.5 \%)$ & $204(39 \%)$ \\
\hline Triphasic & - & $24(4.6 \%)$ & $6(1.1 \%)$ & $29(5.5 \%)$ & $59(11 \%)$ \\
\hline$n$ & $21(4 \%)$ & $285(54.5 \%)$ & $172(32.9 \%)$ & 44 (8.4\%) & $522(100 \%)$ \\
\hline
\end{tabular}


Table 3 Inter-group comparison according to the morphology of the glucose curve in normal glucose tolerance individuals. Data are shown as mean \pm S.E.M.

\begin{tabular}{|c|c|c|c|c|c|}
\hline & \multicolumn{4}{|c|}{ Morphology of the glucose curve } & \multirow[b]{2}{*}{$\boldsymbol{P}<$} \\
\hline & Monotonous & Monophasic & Biphasic & Triphasic & \\
\hline$n$ & 21 & 285 & 172 & 44 & 0.5 \\
\hline $\operatorname{Sex}(M / F)$ & $10 / 11$ & $146 / 139$ & $98 / 74$ & $26 / 18$ & 0.54 \\
\hline Age (years) & $12.5 \pm 0.47$ & $11.2 \pm 0.16$ & $10.7 \pm 0.21$ & $10.4 \pm 0.41$ & 0.01 \\
\hline BMl $\left(\mathrm{kg} / \mathrm{m}^{2}\right)^{\star, \dagger, \downarrow, \S}$ & $31.9 \pm 1.24$ & $28.9 \pm 0.3$ & $27.3 \pm 0.31$ & $28.12 \pm 0.7$ & 0.0001 \\
\hline BMI z-score (SDS) & $2.24 \pm 0.08$ & $2.22 \pm 0.02$ & $2.12 \pm 0.04$ & $2.27 \pm 0.06$ & 0.048 \\
\hline Waist circumference $(\mathrm{cm})$ & $87 \pm 2$ & $84.3 \pm 0.82$ & $82 \pm 0.85$ & $82.6 \pm 2.26$ & 0.2 \\
\hline Uric acid $(\mathrm{mg} / \mathrm{dl})$ & $5.51 \pm 0.36$ & $5.42 \pm 0.08$ & $5.15 \pm 0.09$ & $5.51 \pm 0.32$ & 0.1 \\
\hline Total cholesterol (mg/dl) & $153.3 \pm 5.2$ & $154 \pm 1.81$ & $154.4 \pm 3$ & $160.2 \pm 4.4$ & 0.7 \\
\hline HDL-cholesterol (mg/dl) & $48.9 \pm 2.3$ & $53.3 \pm 0.86$ & $53.2 \pm 1.19$ & $51 \pm 1.36$ & 0.4 \\
\hline LDL-cholesterol (mg/dl) & $86.8 \pm 4.9$ & $85.2 \pm 1.55$ & $85.6 \pm 1.95$ & $92.4 \pm 4.25$ & 0.4 \\
\hline Triglycerides $(\mathrm{mg} / \mathrm{dl})$ & $87.9 \pm 7.6$ & $82.8 \pm 2.1$ & $78.8 \pm 2.65$ & $86 \pm 4.90$ & 0.4 \\
\hline $\mathrm{ALT}(\mathrm{Ul} / \mathrm{ml})$ & $23.3 \pm 1.82$ & $24.5 \pm 0.79$ & $23.5 \pm 0.53$ & $24.6 \pm 1.17$ & 0.8 \\
\hline AST (Ul/ml) & $26 \pm 3.41$ & $26.1 \pm 1.64$ & $24.1 \pm 1.07$ & $23.9 \pm 1.81$ & 0.8 \\
\hline $\mathrm{FPG}(\mathrm{mg} / \mathrm{dl})^{\dagger}$ & $69.9 \pm 1.52$ & $73.5 \pm 0.43$ & $75.3 \pm 0.58$ & $74.3 \pm 1.31$ & 0.006 \\
\hline 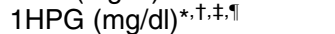 & $104.1 \pm 1.81$ & $129 \pm 1.3$ & $112.1 \pm 1.50$ & $97.0 \pm 2.48$ & 0.0001 \\
\hline $2 \mathrm{HPG}(\mathrm{mg} / \mathrm{dl})^{*, \mp}$ & $116.1 \pm 2.19$ & $105.3 \pm 0.91$ & $112.9 \pm 0.89$ & $100.8 \pm 2.37$ & 0.0001 \\
\hline $\mathrm{I}_{0}(\mu \mathrm{Ul} / \mathrm{ml})$ & $18.7 \pm 3.5$ & $14.6 \pm 0.72$ & $13.4 \pm 0.85$ & $13.1 \pm 0.87$ & 0.4 \\
\hline $\mathrm{I}_{30}(\mu \mathrm{Ul} / \mathrm{ml})$ & $89.5 \pm 22.6$ & $114.3 \pm 4.58$ & $120.3 \pm 5.86$ & $147.7 \pm 13.02$ & 0.02 \\
\hline $\mathrm{I}_{120}(\mu \mathrm{Ul} / \mathrm{ml})$ & $126.5 \pm 19.6$ & $17.6 \pm 3.3$ & $77.3 \pm 3.4$ & $64.02 \pm 7.01$ & 0.002 \\
\hline HOMA-IR & $3.28 \pm 0.65$ & $2.67 \pm 0.12$ & $2.52 \pm 0.16$ & $2.44 \pm 0.17$ & 0.4 \\
\hline $\mathrm{OGIS}^{\ddagger}$ & $469 \pm 21.37$ & $479.2 \pm 4.8$ & $499.8 \pm 5.5$ & $475.4 \pm 13.35$ & 0.03 \\
\hline ISI & $4.74 \pm 0.66$ & $4.66 \pm 0.25$ & $5.14 \pm 0.33$ & $4.38 \pm 0.30$ & 0.6 \\
\hline HIRI & $4.11 \pm 0.94$ & $6.19 \pm 0.26$ & $6.43 \pm 0.32$ & $7.61 \pm 0.70$ & 0.02 \\
\hline $\mathrm{MISI}^{*, \dagger, \neq, \S}$ & $0.004 \pm 0.002$ & $0.54 \pm 0.02$ & $0.38 \pm 0.02$ & $0.49 \pm 0.05$ & 0.0001 \\
\hline$G T_{p}$ & $1.75 \pm 0.14$ & $0.99 \pm 0.05$ & $1.37 \pm 0.36$ & $1.15 \pm 0.11$ & 0.4 \\
\hline $\mid \mathrm{GI}$ & $15.89 \pm 19.41$ & $31.83 \pm 1.46$ & $32.3 \pm 2.81$ & $46.18 \pm 4.72$ & 0.007 \\
\hline $\mathrm{AUC}_{\mathrm{G}}{ }^{\star,+, \neq, \|}$ & $101.15 \pm 1.52$ & $116.7 \pm 0.86$ & $109.9 \pm 0.91$ & $108.6 \pm 1.87$ & 0.0001 \\
\hline$A \cup C^{\ddagger}$ & $93.66 \pm 18.5$ & $91.74 \pm 3.05$ & $77.52 \pm 3.12$ & $88 \pm 6.90$ & 0.03 \\
\hline$A \cup C_{\mid} / A \cup C_{G}$ & $1.68 \pm 0.22$ & $1.67 \pm 0.06$ & $1.85 \pm 0.10$ & $1.59 \pm 0.13$ & 0.3 \\
\hline $\mathrm{DI}_{\mathrm{ISI}} \|$ & $121.8 \pm 31.8$ & $117.3 \pm 8.07$ & $117.6 \pm 25.3$ & $177 \pm 19.7$ & 0.0001 \\
\hline ISSI-2 & $2.96 \pm 0.31$ & $2.87 \pm 0.13$ & $2.88 \pm 0.11$ & $2.94 \pm 0.12$ & 0.6 \\
\hline
\end{tabular}

FPI, fasting plasma insulin; FPG, fasting plasma glucose; ALT, alanine aminotransferase; AST, aspartate aminotransferase

Statistical significance refers to the ANOVA test followed by the Bonferroni post-hoc comparison (on logarithmically transformed variables before analysis) among patients presenting with different morphologies of the glucose curves as follows: ${ }^{*}$ Monotonous vs monophasic (BMI, $P<0.03$; $1 \mathrm{HPG}, P<0.0001$; 2HPG, $P<0.004$; MISI, $\left.P<0.0001 ; \mathrm{AUC}_{\mathrm{G}}, P<0.0001\right)$; ${ }^{\dagger}$ Monotonous vs biphasic $(\mathrm{BMI}, P<0.0001 ; \mathrm{FPG}, P<0.01 ; \mathrm{MISI}, P<0.0001 ; \mathrm{AUC}, P<0.027)$; ${ }^{\ddagger}$ Monotonous vs triphasic (BMI, $P<0.016$; $2 \mathrm{HPG}, P<0.0001 ; I_{30}, P<0.03$; MISI, $P<0.0001 ;$ IGI, $\left.P<0.005 ; \mathrm{HIRI}, P<0.016\right)$; ${ }^{\S}$ Monophasic vs biphasic (BMI, $P<0.004$; $1 \mathrm{HPG}, P<0.0001$; MISI, $P<0.0001$; 2HPG, $P<0.0001$; AUC,$P<0.0001$; AUC,$P<0.02$; OGIS, $P<0.05$ ); "Monophasic vs triphasic (1HPG, $P<0.0001$; IGI, $P<0.06$; AUC $\left._{\mathrm{G}}, P<0.001\right)$; "Biphasic vs triphasic (1HPG, $P<0.0001$ ).

individuals. Indeed, they presented with greater values of $1 \mathrm{HPG}, 2 \mathrm{HPG}$ and $\mathrm{AUC}_{\mathrm{G}}$ and a lower glucose DI as estimated by the ISSI-2. These subjects may belong to a class of increased risk for altered glucose metabolism because of both altered hepatic and muscle insulin sensitivity.

Conversely, patients presenting with biphasic morphology of the glucose curve and monophasic insulin had the lowest values of 1HPG, 2HPG and $\mathrm{AUC}_{\mathrm{G}}$, with values of muscle insulin sensitivity and glucose DIs in the upper range (Fig. 2). Thus, they may exhibit a metabolic phenotype at lower risk for altered glucose metabolism. The biphasic shape of glucose tended to be associated with better insulin sensitivity, but this trend achieved the statistical significance only when insulin sensitivity was estimated according to Mari's model. Tschritter et al. (6) noticed that individuals with biphasic morphology of the glucose curve had a more efficient disposal of the glucose concentrations to baseline.
Intriguing results came into view as well, when individuals with either monophasic (M) or biphasic (B) glucose shape were categorised according to the time when the glucose peaked, either at $30^{\prime}\left(\mathrm{M}_{\mathrm{G} 30}\right.$ and $\left.\mathrm{B}_{\mathrm{G} 30}\right)$ or $60^{\prime}\left(\mathrm{M}_{\mathrm{G} 60}\right.$ and $\left.\mathrm{B}_{\mathrm{G} 60}\right)$.

$\mathrm{M}_{\mathrm{G} 30}$ had the lowest values of $\mathrm{AUC}_{\mathrm{G}}$ and the best DI as estimated by the ISSI-2, supporting the concept demonstrated elsewhere that the more quickly the plasma glucose concentration returns to or below the fasting glucose level following glucose ingestion, the lower is the risk for future diabetes (2).

$\mathrm{M}_{\mathrm{G} 60}$ individuals had lower levels of $\mathrm{I}_{30}$ and, consequently, of IGI and HIRI. $\mathrm{B}_{\mathrm{G} 60}$ had the highest values of HOMA-IR and a value of HIRI in the upper levels, again suggesting altered gluconeogenesis associated with such phenotype. Reduced muscle insulin sensitivity is likely to cause increased 2HPG in $\mathrm{B}_{\mathrm{G} 60}$ individuals (Fig. 3).

With regard to the clinical meaning of glucose peaking at $1 \mathrm{~h}$, a growing body of literature supports 

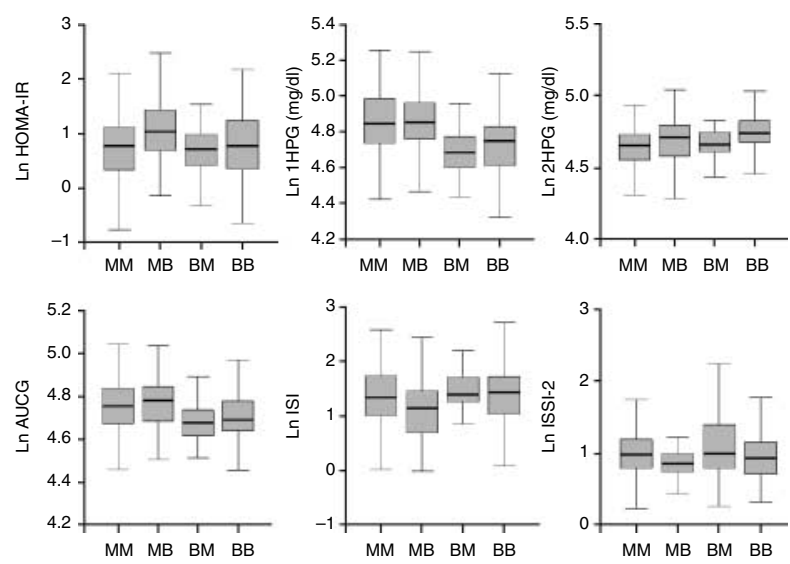

Figure 2 Box plots of parameters of insulin action, secretion and glucose tolerance (expressed as $I n$ ) in the group of individuals with monophasic (MM) or biphasic (BB) morphologies of both glucose and insulin curves or of monophasic glucose and biphasic insulin (MB) or vice versa (BM). ANOVA demonstrated significant differences among groups with monophasic and biphasic morphologies of the glucose and insulin curves in HOMA-IR $(P<0.001)$, HIRI $(P<0.04)$, 1HPG $(P<0.0001)$; 2HPG

$(P<0.0001) ; \mathrm{AUC}_{\mathrm{G}}(P<0000.1)$, ISI $(P<0.001), \mathrm{I}_{120}(P<0.0001)$, AUC $_{1}(P<0.02)$, MISI $(P<0.0001)$ and ISSI-2 $(P=0.004)$. Statistical significance at the post-hoc test was as follows: HOMA-IR was the greatest in the MB group ( $P$ ranging from 0.05 to 0.001$)$. MM and MB individuals had greater $1 \mathrm{HPG}(P<0.0001$ in all the comparisons of monophasic glucose vs biphasic); 2HPG was lower in MM individuals compared with BB patients $(P<0.0001)$. $\mathrm{AUC}_{\mathrm{G}}$ was lower in $\mathrm{BM}$ and $\mathrm{BB}$ groups ( $P$ ranging from 0.005 to 0.001 ). Individuals with biphasic glucose had greater ISI than MB individuals ( $P=0.001$ and 0.01 respectively). MM subjects were more sensitive to insulin than MB subjects $(P<0.007)$. The glucose disposition index calculated as ISSI-2 was the lowest in MB individuals $(P=0.002$ vs both $\mathrm{MM}$ and $\mathrm{BM})$.

the role of exaggerated 1HPG as risk factor for diabetes $(16,17,18)$. Novel cut-off value for 1HPG $(\geq 155 \mathrm{mg} / \mathrm{dl})$ would identify a novel class of prediabetes, particularly when associated with features of the metabolic syndrome $(17,18)$. In our group of individuals with monophasic glucose curve, 1HPG $(\beta=0.546)$ and triglycerides $(\beta=0.164)$ entered a regression model predicting 2HPG $\left(R^{2}=0.32\right.$, $P>0.0001)$. In the model, age, BMI $z$-score, HOMA-IR, total and HDL-cholesterol and waist circumference were excluded variables.

The triphasic morphology was associated with the lowest concentration of $2 \mathrm{HPG}$, the highest of insulin at $30^{\prime}$, the greatest values of IGI and HIRI and the best DI. Indeed, calculation of IGI and HIRI requires insulin concentration at $30^{\prime}$. Individuals belonging to this group had a greater insulin release as estimated by the IGI, which, in turn, would protect them against development of diabetes. These individuals seem to be able to compensate fully for insulin resistance as evident by their DI. DI is the best predictor for altered glucose also in the youth (19). In the study by Kanauchi et al. (4), NGT individual presented more frequently biphasic or two-peak (termed triphasic in our study) morphologies of the curve.

With respect to previous studies (4-7), we tried to deeper phenotype obese patients by matching morphologies of the glucose curve with those of the insulin curve and characterising them by the time of glucose peaking. We also investigated associations between morphologies and indexes of insulin action and secretion, commonly used in epidemiological settings. In one such study, an index of the morphology, associated with glucose tolerance, was developed (5). Successively, Kanauchi et al. (4) investigated the association between morphology and time of glucose peaking, as we did. More recently, Abdul-Ghani et al. (5) explored the relationship between morphology and rate of glucose declining toward or below preload values.

Findings from our analysis suggest that subjects with monophasic shape of the glucose curve and biphasic insulin are at increased risk for altered glucose metabolism, and, on the contrary, those presenting with biphasic glucose and monophasic insulin are at lower risk. Owing to the lack of longitudinal data, our findings can provide the rationale for future confirmatory studies. Moreover, we are aware that some associations (i.e. with the $\mathrm{AUC}_{\mathrm{G}}$ ) may be expected and could be due to co-linearity. Nevertheless, the suspect emerges that some formulae may adapt better to estimate insulin metabolism in individuals with certain
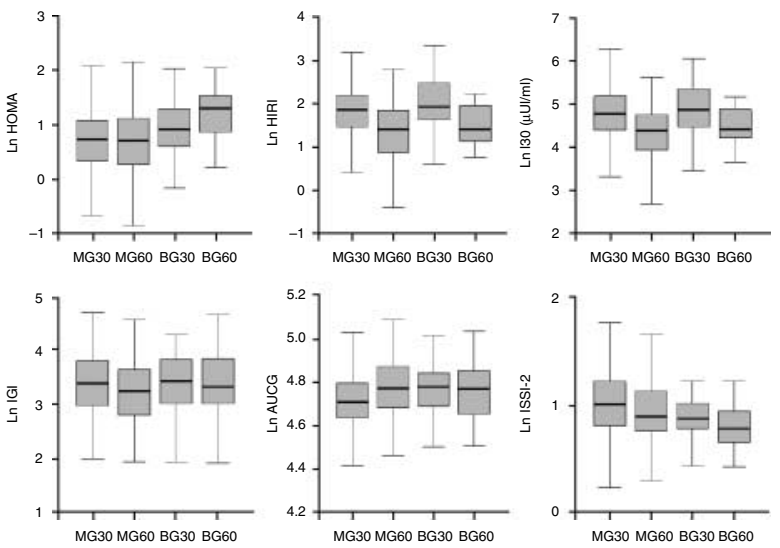

Figure 3 Box plots of parameters of insulin action, secretion and glucose tolerance (expressed as $\mathrm{In}$ ) in the group of individuals with monophasic (M) or biphasic (B) morphology of the glucose curve and plasma glucose peaking at $30^{\prime}\left(\mathrm{M}_{\mathrm{G} 30}\right.$ or $\left.\mathrm{B}_{\mathrm{G} 30}\right)$ or $60^{\prime}\left(\mathrm{M}_{\mathrm{G} 60}\right.$ or $\left.B_{G 60}\right)$. Differences at the ANOVA were observed in 1HPG, HIRI, $I_{30}$, $\mathrm{I}_{120}\left(P<0.0001\right.$ for all the comparisons), 2HPG $(P<0.05), \mathrm{AUC}_{\mathrm{G}}$ $(P<0.003), \mathrm{AUC}_{\text {I }}(P<0.009)$, OGIS $(P<0.04)$, ISI $(P<0.014)$, MISI $(P<0.006)$, IGI $(P<0.003)$ and ISSI-2 $(P=0.005)$. $\mathrm{B}_{\mathrm{G} 60}$ had the highest value of HOMA-IR compared with $\mathrm{M}_{\mathrm{G} 30}$ and $\mathrm{M}_{\mathrm{G} 60}$ $\left(P<0.03\right.$ for both). $\mathrm{M}_{\mathrm{G} 30}$ had the lowest values of $A \cup C_{\mathrm{G}}$ compared with $\mathrm{M}_{\mathrm{G} 60}(P<0.02)$ and $\mathrm{B}_{\mathrm{G} 30}(P<0.04)$. $\mathrm{I}_{30}$ was the lowest in MG60 $\left(P<0.0001\right.$ vs $\mathrm{M}_{\mathrm{G} 30}$ and $\mathrm{B}_{\mathrm{G} 30} ; \mathrm{B}_{\mathrm{G} 30}$ vs $\left.\mathrm{B}_{\mathrm{G} 60}, P<0.04\right)$. HIRI was the lowest in $\mathrm{M}_{\mathrm{G} 60}$ vs $\mathrm{M}_{\mathrm{G} 30}$ and $\mathrm{B}_{\mathrm{G} 30}(P<0.0001)$. $\mathrm{M}_{\mathrm{G} 30}$ and $\mathrm{M}_{\mathrm{G} 60}$ differed significantly in IGI $(P<0.01)$. The best disposition index as calculated by ISSI-2 was observed in $\mathrm{M}_{\mathrm{G} 30}$ individuals $\left(P=0.03\right.$ vs $\mathrm{B}_{\mathrm{G} 30}$ and $P=0.004$ vs $\left.\mathrm{B}_{\mathrm{G} 60}\right)$. 
morphology of the glucose curve and may not work efficiently in others. For instance, the OGIS model is based on the concept of a single compartment in which there is a linear association between concentration of plasma glucose and that of insulin. Moreover, it assumes that in the last hour of the OGTT, the glucose concentration exhibits a clear down slope. In some individuals (i.e. those with biphasic or triphasic morphologies), the relationship between glucose and insulin may be perturbed by an altered milieu of gut hormones. Furthermore, in patients belonging to these categories, plasma glucose does not display a down slope as postulated in Mari's model.

Matsuda's index may also not perform adequately in subjects with biphasic and upward monotonous glucose morphologies. The ISI composite presupposes that the initial rise of plasma glucose concentration is mainly determined by the HIRI and by the suppression of EGP in response to the insulin that is secreted in response to hyperglycaemia. Mean values of glucose and insulin during the OGTT would resume what happens for the subsequent $60^{\prime}-120^{\prime}$, when EGP is maximally suppressed and remains constantly suppressed (20). Therefore, the rate of decline in plasma glucose concentration from its peak value to its nadir primarily reflects glucose uptake by peripheral tissues, muscle and the insulin secretory response to hyperglycaemia. Nevertheless, the intersection between insulin sensitivity and secretion may be more complex than that in some subjects in whom EGP may not be adequately suppressed. Indeed, during the OGTT, the suppression of EGP is much less complete than during the euglycaemic clamp (20).

Our analysis was done with the aim of enlarging the spectrum of categories for altered glucose metabolism and providing clinicians with more simple means to estimate risk for reduced insulin action and secretion instead of mathematical formulae. Our study cannot definitively answer the question whether and to what extent different morphologies of the glucose curve reflect faithfully inter-individual differences in insulin action and secretion. To answer such a question, there is need for a cohort study in which both are estimated by clamp techniques and use of tracers. However, our findings strongly support that morphology, intersection of different morphologies and time of glucose peak identify different metabolic profiles of risk for altered glucose metabolism.

We are aware of several other caveats affecting our study that was performed on young obese patients. First, HOMA-IR, ISI and IGI are the only indexes of insulin action and secretion validated so far in youth (21). No information was provided on reproducibility of the test and intra-individual variability of glucose morphology. Indeed, if patterns of glucose and insulin shapes are not reproducible, in turn, such analysis will have limited applicability.
Glucose tolerance estimated by the test may vary significantly in the same subject and its reproducibility is particularly poor among those adolescents with the greatest degree of apparent abnormality (22).

A complete analysis of the morphology would consider data on the observational interval of $180 \mathrm{~min}$ or longer.

We also did not provide information on several other pivotal factors, which modulate the rate of glucose increase and decrease, namely glucose absorption and gastric empting, components of $\beta$-cell function, release of gastro-intestinal hormones (i.e. glucagon, glucagonlike peptide-1 and gastric inhibitory peptide) and sensitivity of their receptors for their ligands.

In conclusion, different morphologies of the glucose curve, their association with morphologies of the insulin curve and time of glucose peak may represent useful means to describe different phenotypes of glucose tolerance, insulin action and secretion in young obese individuals. An increased risk for altered glucose metabolism may be suspected in individuals with monophasic glucose but biphasic insulin or in those presenting with an exaggerated glucose peak at $1 \mathrm{~h}$.

Nevertheless, cohort study estimating insulin action and secretion by using gold standard techniques are needed to understand whether novel abnormalities identified during the OGTT represent something valuable in the clinical practice.

The OGTT is useful, in research settings, to estimate systemic insulin sensitivity and $\beta$-cell function in large population studies, but findings from our study highlight the importance of the morphology before applying common indexes of insulin action and secretion.

\section{Supplementary data}

This is linked to the online version of the paper at http://dx.doi.org/10. 1530/EJE-11-0827.

\section{Declaration of interest}

The authors have nothing to declare. The contents of this manuscript have not been copyrighted or published previously, except as the abstract, which was presented at the 47th meeting of the European Association for the Study of Diabetes.

\section{Funding}

The work was supported by a grant to M Manco from the Italian Ministry of Health (RF-OPG-20081142374).

\section{Author contribution statement}

All authors have directly participated in the execution and analysis of the study. The authors' responsibilities are as follows: M Manco and G Nolfe: concept and design of the study; data analysis, drafting of the manuscript and revision for important intellectual content; M R Spreghini: data collection; M R Spreghini, R Wietrzycowska Sforza and G Morino: patients' follow-up and critical revision. 


\section{References}

1 Abdul-Ghani MA \& DeFronzo RA. Plasma glucose concentration and prediction of future risk of type 2 diabetes. Diabetes Care 2009 32 S194-S198. (doi:10.2337/dc09-S309)

2 Abdul-Ghani MA, Matsuda M. Balas B \& DeFronzo RA. Muscle and liver insulin resistance indexes derived from the oral glucose tolerance test. Diabetes Care 200730 89-94. (doi:10.2337/dc061519)

3 Abdul-Ghani MA, Williams K, DeFronzo R \& Stern M. Risk of progression to type 2 diabetes based on relationship between postload plasma glucose and fasting plasma glucose. Diabetes Care 200629 1613-1618. (doi:10.2337/dc05-1711)

4 Kanauchi M, Kimura K, Kanauchi K \& Saito Y. Beta-cell function and insulin sensitivity contribute to the shape of plasma glucose curve during an oral glucose tolerance test in non-diabetic individuals. International Journal of Clinical Practice $2005 \mathbf{5 9}$ 427-432. (doi:10.1111/j.1368-5031.2005.00422.x)

5 Abdul-Ghani MA, Stern MP, Lyssenko V, Tuomi T, Groop L \& Defronzo RA. Minimal contribution of fasting hyperglycemia to the incidence of type 2 diabetes in subjects with normal 2-h plasma glucose. Diabetes Care 201033 557-561. (doi:10.2337/dc091145)

6 Tschritter O, Fritsche A, Shirkavand F, Machicao F, Häring H \& Stumvoll M. Assessing the shape of the glucose curve during an oral glucose tolerance test. Diabetes Care 200326 1026-1033. (doi:10.2337/diacare.26.4.1026)

7 Zhou W, Gu Y, Li H \& Luo M. Assessing 1-h plasma glucose and shape of the glucose curve during oral glucose tolerance test. European Journal of Endocrinology 2006155 191-197. (doi:10. 1530/eje.1.02188)

8 Kuczmarski RJ, Ogden CL, Guo SS, Grummer-Strawn LM, Flegal KM, Mei Z, Wei R, Curtin LR, Roche AF \& Johnson CL. CDC Growth Charts for the United States: methods and development. Vital and Health Statistics. Series 11, Data from the National Health Survey 2000246 1-190.

9 Expert Committee on the Diagnosis and Classification of Diabetes Mellitus. Report of the Expert Committee on the diagnosis and classification of diabetes mellitus. Diabetes Care 200326 S5-S20. (doi:10.2337/diacare.26.2007.S5)

10 Sluiter WJ, Erkelens DW, Terpstra P, Reitsma WD \& Doorenbos H. Glucose tolerance and insulin release, a mathematical approach. II. Approximation of the peripheral insulin resistance after oral glucose loading. Diabetes $1976 \quad 25$ 245-249. (doi:10.2337/ diabetes.25.4.245)

11 Matthews DR, Hosker JP, Rudenski AS, Naylor BA, Treacher DF \& Turner RC. Homeostasis model assessment: insulin resistance and beta-cell function from fasting plasma glucose and insulin concentrations in man. Diabetologia 198528 412-419. (doi:10. 1007/BF00280883)

12 Matsuda M \& DeFronzo RA. Insulin sensitivity indices obtained from oral glucose tolerance testing: comparison with the euglycemic insulin clamp. Diabetes Care 199922 1462-1470. (doi:10.2337/diacare.22.9.1462)
13 Mari A, Pacini G, Murphy E, Ludvik B \& Nolan JJ. A model-based method for assessing insulin sensitivity from the oral glucose tolerance test. Diabetes Care 200124 539-548. (doi:10.2337/ diacare.24.3.539)

14 Phillips DI, Clark PM, Hales CN \& Osmond C. Understanding oral glucose tolerance: comparison of glucose or insulin measurements during the oral glucose tolerance test with specific measurements of insulin resistance and insulin secretion. Diabetic Medicine 199411 286-292. (doi:10.1111/j. 1464-5491.1994.tb00273.x)

15 Retnakaran R, Qi Y, Goran MI \& Hamilton JK. Evaluation of proposed oral disposition index measures in relation to the actual disposition index. Diabetic Medicine 200926 1198-1203. (doi:10. 1111/j.1464-5491.2009.02841.x)

16 Abdul-Ghani MA, Lyssenko V, Tuomi T, Defronzo RA \& Groop L. The shape of plasma glucose concentration curve during OGTT predicts future risk of type 2 diabetes. Diabetes/Metabolism Research and Reviews 201026 280-286. (doi:10.1002/dmrr.1084)

17 Abdul-Ghani MA, Abdul-Ghani T, Ali N \& Defronzo RA. One-hour plasma glucose concentration and the metabolic syndrome identify subjects at high risk for future type 2 diabetes. Diabetes Care 200831 1650-1655. (doi:10.2337/dc08-0225)

18 Manco M, Panunzi S, Macfarlane DP, Golay A, Melander O, Konrad T, Petrie JR \& Mingrone G. Relationship between Insulin Sensitivity and Cardiovascular Risk (RISC) Consortium. One-hour plasma glucose identifies insulin resistance and beta-cell dysfunction in individuals with normal glucose tolerance: crosssectional data from the Relationship between Insulin Sensitivity and Cardiovascular Risk (RISC) study. Diabetes Care 201033 2090-2097. (doi:10.2337/dc09-2261)

19 Cali AM, Man CD, Cobelli C, Dziura J, Seyal A, Shaw M, Allen K, Chen S \& Caprio S. Primary defects in beta-cell function further exacerbated by worsening of insulin resistance mark the development of impaired glucose tolerance in obese adolescents. Diabetes Care 200932 456-461. (doi:10.2337/dc08-1274)

20 Ferrannini E, Bjorkman O, Reichard GA Jr, Pilo A, Olsson M, Wahren J \& DeFronzo RA. The disposal of an oral glucose load in healthy subjects: a quantitative study. Diabetes $198534580-588$. (doi:10.2337/diabetes.34.6.580)

21 Yeckel CW, Weiss R, Dziura J, Taksali SE, Dufour S, Burgert TS, Tamborlane WV \& Caprio S. Validation of insulin sensitivity indices from oral glucose tolerance test parameters in obese children and adolescents. Journal of Clinical Endocrinology and Metabolism 200489 1096-1101. (doi:10.1210/jc.2003$031503)$

22 Libman IM, Barinas-Mitchell E, Bartucci A, Robertson R \& Arslanian S. Reproducibility of the oral glucose tolerance test in overweight children. Journal of Clinical Endocrinology and Metabolism 200893 4231-4237. (doi:10.1210/jc.2008-0801)

Received 3 August 2011

Accepted 18 October 2011 